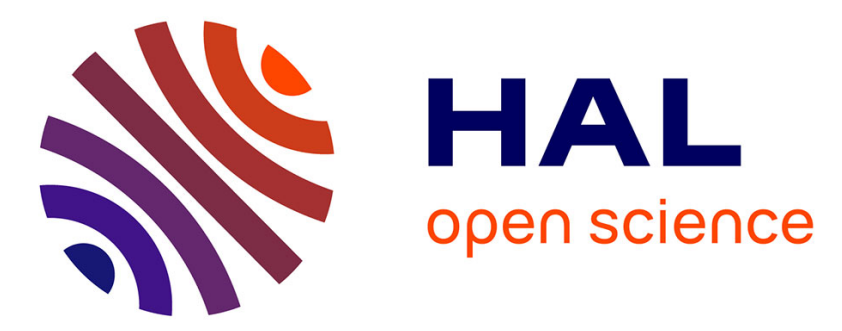

\title{
Enhancing microperoxidase activity and selectivity: immobilization in metal-organic frameworks
}

Effrosyni Gkaniatsou, Christian Serre, Jean-Pierre Mahy, Nathalie Steunou, Rémy Ricoux, Clémence Sicard

\section{To cite this version:}

Effrosyni Gkaniatsou, Christian Serre, Jean-Pierre Mahy, Nathalie Steunou, Rémy Ricoux, et al.. Enhancing microperoxidase activity and selectivity: immobilization in metal-organic frameworks. Journal of Porphyrins and Phthalocyanines, 2019, 23, pp.718-728. 10.1142/s1088424619300106 . hal03110870

\author{
HAL Id: hal-03110870 \\ https://hal.science/hal-03110870
}

Submitted on 14 Jan 2021

HAL is a multi-disciplinary open access archive for the deposit and dissemination of scientific research documents, whether they are published or not. The documents may come from teaching and research institutions in France or abroad, or from public or private research centers.
L'archive ouverte pluridisciplinaire HAL, est destinée au dépôt et à la diffusion de documents scientifiques de niveau recherche, publiés ou non, émanant des établissements d'enseignement et de recherche français ou étrangers, des laboratoires publics ou privés. 


\title{
Enhancing microperoxidase activity and selectivity: Immobilization in Metal-Organic Frameworks
}

\author{
Effrosyni Gkaniatsou ${ }^{a}$, Christian Serre ${ }^{b}$, Jean-Pierre Mahy*c ${ }^{\mathrm{c}}$, Nathalie Steunou ${ }^{\mathrm{a}}$, Rémy \\ Ricoux $^{\mathrm{c}}$ and Clémence Sicard ${ }^{* a}$
}

\begin{abstract}
${ }^{a}$ Institut Lavoisier de Versailles, UVSQ, CNRS, Université Paris-Saclay, 45 avenue des Etat-Unis, Versailles, France
${ }^{b}$ Institut des Matériaux Poreux de Paris, UMR-8004 CNRS-ENS-ESPCI, PSL research university, 75005, Paris, France

${ }^{c}$ Laboratoire de Chimie Bioorganique et Bioinorganique, Institut de Chimie Moléculaire et des Matériaux d'Orsay,

UMR 8182, Université Paris Sud, Université Paris-Saclay, 91405 Orsay Cedex, France
\end{abstract}

Received date (to be automatically inserted after your manuscript is submitted)

Accepted date (to be automatically inserted after your manuscript is accepted)

\begin{abstract}
Microperoxidases 8 (MP8) and 11 (MP11) are heme-containing peptides obtained by the proteolytic digestion of Cytochrome c. They act as mini-enzymes that combine both peroxidase-like and Cytochrome P450-like activities that may be useful in the synthesis of fine chemicals or in the degradation of enviromental pollutants. However, their use is limited by their instability in solution due to (i) the bleaching of the heme in the presence of an excess of $\mathrm{H}_{2} \mathrm{O}_{2}$, (ii) the decoordination of the distal histidine ligand of the iron under acidic conditions and, (iii) their tendency to aggregate in aqueous alkaline solutions, even at low concentrations. Additionally, both MP8 and MP11 show a relatively low selectivity, due to the lack of control of the substrates by a specific catalytic pocket on the distal face of the heme. Both stability and selectivity issues can be effectively addressed by immobilization of microperoxidases in solid matrices, which can also lead to their possible recycling from the reaction medium. Considering their relatively small size, the pore inclusion of MPs into Metal-Organic Frameworks appeared to be more adequate compared to other immobilization methods that have been widely investigated for decades. The present minireview describes the catalytic activities of MP8 and MP11, their limitations and various results describing their immobilization of MPs into MOFs. It led to MP11- or MP8@MOF hybrid materials that display a good activity in the oxidation of dyes and phenol derivatives, with a remarkable recyclability due to the stabilization of the MPs inside the MOF cavities. An example of selective oxidation of dyes according to their charge by MP8@MOF hybrid materials is also highlighted.
\end{abstract}

KEYWORDS: biocatalysis, microperoxidases, immobilization, metal-organic frameworks (MOFs), oxidation.

\footnotetext{
*Correspondence to: Prof. Jean-Pierre Mahy, Laboratoire de Chimie Bioorganique et Bioinorganique, Institut de Chimie Moléculaire et des Matériaux d'Orsay, UMR 8182 CNRS, Université Paris-Sud 11, Bât. 420, 91405, Orsay cedex, France. Phone: (33) [1] 69 15 74 21, Fax: (33) [1] 691572 81, e-mail: ipmahy@icmo.u-psud.fr.

Dr. Clémence Sicard, Institut Lavoisier de Versailles, UMR 8180 CNRS-UVSQ, Batiment Lavoisier, 45 avenue des Etats-Unis, 78035 Versailles cedex, France. Phone: (33) [1] 3925 43 71, e-mail: clemence.sicard@uvsq.fr
} 


\section{INTRODUCTION}

The use of biocatalysts, such as enzymes, in the synthesis of high added-value chemicals and for environmental depollution purposes can be very advantageous. Indeed, enzymes are very selective catalysts that are able to transform substrates with high turn-over numbers, under mild operational conditions (ambient temperature, atmospheric pressure and aqueous solution) that simplify catalytic operations and lower their cost.[1-3] However, the soluble forms of enzymes are not easily removable from the reaction mixtures and require time-consuming and expensive separation steps to isolate the pure products (e.g. in the production of fine chemicals). Moreover, soluble forms do not allow a repetitive use, which increases the overall cost of the procedure. [4] These drawbacks can be effectively addressed by the immobilization of enzymes in solid supports, which provides an easier handling of enzymes (shaping of the biocatalyst), enables their separation from the products and their recycling and reuse, resulting in more cost-effective processes. Moreover, the solid support used for the immobilization may stabilize and protect the enzymes, under nonnatural environments (high temperatures, organic solvents, denaturating factors, extreme $\mathrm{pH}$ ).

Metalloporphyrins are broadly distributed in nature and iron(III) protoporphyrin IX or heme (Fig. 1) stands among the most common ones, as it constitutes the prosthetic group of the heme enzymes family or hemoproteins. The main functions of heme enzymes in living cells are electron and oxygen transport and they thus constitute a subclass of oxido-reductases. Heme enzymes with an oxidative activity can be generally divided into peroxidases that use peroxides (typically $\mathrm{H}_{2} \mathrm{O}_{2}$ ) to oxidize substrates (e.g. horseradish peroxidase, $\mathrm{HRP}$ ) and mono-oxygenases that use $\mathrm{O}_{2}$ to oxygenate substrates (e.g. Cytochrome P450s).[5-7]

\section{Insert Figure 1}

This review is focused on a sub-class of heme-containing enzymes, named microperoxidases and more specifically on microperoxidase 8 (MP8) and microperoxidase 11 (MP11). These mini-enzymes combine both types of activities, i.e. peroxidase-like and mono-oxygenase-like activities.

\section{MICROPEROXIDASES: STATE OF THE ART}

Microperoxidases (MPs) are heme-bound peptides obtained by the proteolytic digestion of Cytochrome c (Cyt c). Seven different MPs have been isolated and consist of an iron protoporphyrin IX linked to a peptide, comprising a variable number of amino acids, that derive from Cytochrome c; MP5 (residues 13-14/17-18) MP6 (residues 14-19), MP7 (residues 14-20), MP8 (residues 14-21), MP9 (residues 14-22), MP10 (residues 13-22) and MP11 (residues 11-21) (Fig. 2),[8] among which MP8 and MP11 have been the most studied ones. It has been shown that the polypeptide chain retains a similar conformation to that of the amino acid residues of the parent Cytochrome c protein. The chain is covalently linked to the porphyrin moiety via two thioether bonds between Cys14 and Cys17 and the vinyl substituents of two pyrrole rings (Fig. 2).[9] The peptide chain is shielding the proximal face of the porphyrin, whereas the distal face is completely exposed to the solvent. At neutral $\mathrm{pH}$, the $\varepsilon 2$ nitrogen atom of the imidazole side chain of His 18 is coordinated to the iron(III) on the proximal face of the heme whereas on the distal face, the sixth axial position of the iron(III) is occupied by a water molecule. The loosely bound water molecule can be easily replaced by a variety of ligands (e.g. imidazole, cyanide, thioethers and primary amines). This ability of MPs to bind different ligands has been used as a powerful tool to assess the accessibility of the Fe(III) center in MP complexes with different species (e.g. antibodies), as the coordination results in different absorbing species that can be monitored by UV-vis spectroscopy.[10] The bound $\mathrm{H}_{2} \mathrm{O}$ molecule can be replaced by an oxygen donor (e.g. $\left.\mathrm{H}_{2} \mathrm{O}_{2}\right)$, which leads to the formation of highly oxidized iron-oxo intermediates (Compound I and II)[5] and to peroxidase-like and monooxygenase-like catalytic reactions.[11] 


\section{Insert Figure 2}

The coordination of His 18 as a strong electron donating ligand of the iron(III) is crucial for MPs catalytic function and is $\mathrm{pH}$ dependent, as shown in Figure 3. At low pH, the imidazole of His18 is protonated, which results in a loss of activity. The coordination to the iron(III) occurs at $\mathrm{pH}=4.4$. In the same $\mathrm{pH}$ range the deprotonation of the heme propionates also occurs.[8,12]

\section{Insert Figure 3}

\section{Peroxidase cycle}

The catalytic mechanism of peroxidase-like reactions of MPs is similar to that of common peroxidase enzymes. The first step of the catalytic cycle is the formation of Compound I. In the case of heme peroxidases such as Horseradish peroxidase (HRP) and Cytochrome c peroxidase $(\mathrm{CcP})$, this mechanism is facilitated by a "push-pull" effect, arising from the proximal and distal amino acid residues surrounding the heme. $[5,13,14]$ While many studies have investigated the nature of the intermediates in the catalytic cycle of microperoxidases with $\mathrm{H}_{2} \mathrm{O}_{2}$, [15-17] the exact determination of the formed intermediates has not been clarified. Nonetheless, most reports suggest a similar mechanism to that of common peroxidases.[15] Figure 4 shows the mechanism of Compound I formation in presence of $\mathrm{H}_{2} \mathrm{O}_{2}$, for Cytochrome c peroxidase $(\mathrm{CcP})$ that has been extensively studied over the years. This mechanism highlights the importance of the proximal and distal amino acids in peroxidases. CcP (as MP8 and MP11) has a proximal Histidine (His) ligand coordinated through the $\varepsilon 2 \mathrm{~N}$ atom of the imidazole ring to the Fe(III) center. The aspartate residue (Asp) on the proximal face forms a hydrogen bond with the proximal His, which increases the electron density on the imidazole ring and thereby facilitates the heterolytic cleavage of the $\mathrm{O}-\mathrm{O}$ bond (push effect).[5,18] Meanwhile, the His of the distal pocket acts as a base, withdrawing the proton linked to the $\mathrm{O}_{1}$ atom of $\mathrm{H}_{2} \mathrm{O}_{2}$. The formed distal histidinium can then transfer its proton to the $\mathrm{O}_{2}$ atom of the coordinated hydroperoxide ion, to facilitate the cleavage (pull effect) of the $\mathrm{O}-\mathrm{O}$ bond. This should in principle lead to an $\mathrm{Fe}^{\mathrm{V}}=\mathrm{O}$ species, but it has been shown that, in the case of $\mathrm{CcP}$, a one electron transfer from a proximal tryptophan (Trp) finally leads to the formation of a $\mathrm{Fe}^{\mathrm{IV}}=\mathrm{O}^{\mathrm{CcP}}{ }^{+}$species or Compound I. It is noteworthy that, while CcP Compound I contains a Trp cation radical, in other peroxidases like HRP and MP8 a one electron transfer from the porphyrin ring occurs, leading to compounds I with a porphyrin $\pi$ cation radical.[5-7]

\section{Insert Figure 4}

As already seen from their structure (Fig. 2), neither MP8 nor MP11 have catalytic pockets on their distal face, with amino acids assisting the heterolytic cleavage of the $\mathrm{O}-\mathrm{O}$ bond of $\mathrm{H}_{2} \mathrm{O}_{2}$ and only possess the coordinating His 18 on their proximal face, thus their catalytic efficiency is relatively weaker compared to classic peroxidases. Moreover, the lack of catalytic pocket minimizes their selectivity.[19]

After the formation of Compound I, the next step of the peroxidase-like cycle of microperoxidases concerns the oxidation of a substrate molecule ( $\mathrm{SH})$. A first substrate molecule transfers one electron to Compound I that is reduced into the $\mathrm{Fe}^{\mathrm{IV}}$-oxo species (Compound II), while the substrate is oxidized (S•). (Fig. 5). Finally, one-electron oxidation of a second substrate molecule leads to the reduction of $\mathrm{Fe}^{\mathrm{IV}}$ (Compound II) into $\mathrm{Fe}^{\mathrm{III}}$ (ground state).

\section{Insert Figure 5}

\section{Peroxidase-like reactions}


The main examples of this type of activity were reported with typical peroxidase substrates like 2,2'-azino-bis(3ethylbenzothiazoline-6-sulphonic acid) (ABTS) and 2-methoxyphenol.[20,21] MP8 was also shown to catalyze the nitration of phenolic compounds of biological interest in the presence of $\mathrm{H}_{2} \mathrm{O}_{2}$ and nitrite.[22] The S-oxidation of sulfides to sulfoxides by MP8 and MP11 has also been reported, which however resulted in racemic mixtures, due to the lack of stereo control of the substrate by the amino acids of a catalytic pocket on the distal face of the heme. The mechanism was found to be a two-step oxygen transfer, involving a substrate derived radical cation intermediate.[23] Moreover, microperoxidases (like all peroxidases) are known to enzymatically transform industrial pollutants in less toxic and more easily biodegradable products, such as phenols/halogenated phenols,[24] sulfur compounds[23] and synthetic dyes.[25,26]

\section{Cytochrome $\mathbf{P 4 5 0}$ cycle}

MP8 and MP11 have a double catalytic function and beyond peroxidase-like reactions, they can also catalyze cytochrome P450-like reactions, leading to the formation of monooxygenated products.[5] However, instead of $\mathrm{O}_{2}$ (original oxygen source of Cyt P450)[27] they use $\mathrm{H}_{2} \mathrm{O}_{2}$, thus mimicking the so-called "peroxide shunt" cycle of cytochromes P450s. The first steps of the Cyt P450-like catalytic cycle of microperoxidases are identical to the peroxidase-like mechanism, described above.[28] The distal water molecule bound to the sixth axial position of the iron(III) is easily exchanged with $\mathrm{H}_{2} \mathrm{O}_{2}$, leading to the formation of oxidized intermediate Compound I.[11] The reaction proceeds with Compound I abstracting a hydrogen atom from the substrate molecule (SH), which forms Compound II and a carbon radical (S•).[28,29] The so-called "oxygen rebound" of Compound II to the one electron oxidized substrate molecule $(S \cdot)$ results in the formation of a monooxyganated product (SOH), while the microperoxidase returns to its ground state (Fig. 6).[28,29] It is important to note that monooxygenated products can also result from the peroxidase-like mechanism of the microperoxidase. In that case, two substrate molecules are oxidized $\left(S^{*}\right)$ by Compounds I \& II and the incorporation of the oxygen to the oxidized substrates is via molecular dioxygen or water molecules and not via $\mathrm{H}_{2} \mathrm{O}_{2}$. [28-30] The important difference between these two mechanisms is that with the former only monooxygenated products are formed, while with the latter, they are formed in a mixture also containing dimerized and polymerized products coming from a recombination of the oxidized substrate radicals $(S \cdot) \cdot[28-30]$

\section{Insert Figure 6}

\section{Cytochrome P450-like reactions}

MP8 and MP11 were shown to catalyze the para-hydroxylation of aniline and phenol derivatives in the presence of $\mathrm{H}_{2} \mathrm{O}_{2}$. The mechanism of the reaction was proven to be fully P450-like, through a one-electron oxidation of the substrate by Compound I to give Compound II and a substrate radical that gave rise to the 4-aminophenol.[28] MP8 was also found to catalyze O- and N-dealkylation reactions,[29] through either a peroxidase-like or a Cytochrome P450-like mechanism. In the peroxidase-like mechanism, many polymeric products were identified and the mechanism was based on radical intermediates. However, when the peroxidase-like mechanism was blocked, the formation of polymeric products was strongly prevented, whereas the dealkylation reactions were not affected.[29] Similar results were also observed during the aromatic monooxygenation of hydrocarbons (e.g. benzene, naphthalene and anthracene).[30]

\section{Challenges in the use of MP8 and MP11}

Despite the plethora of chemical reactions that microperoxidases can catalyze, their use in many applications is limited due to their instability in solution. Three main parameters can cause a loss of activity. First, MP8 and MP11 
(like all peroxidases) are deactivated in the presence of an excess of their natural substrate $\mathrm{H}_{2} \mathrm{O}_{2}$. This auto-oxidation is severely destructive for the heme group (heme bleaching) and irreversible. Despite structural variations between different peroxidases, a common deactivation mechanism has been proposed.[18] As seen in Figure 7, in the absence of substrate or in the presence of high concentrations of $\mathrm{H}_{2} \mathrm{O}_{2}, \mathrm{H}_{2} \mathrm{O}_{2}$ reacts with Compound II and generates superoxide radicals that convert Compound II into a highly reactive peroxy-iron(III) porphyrin free radical (Compound III), which is not involved in the peroxidase cycle.[31-33] After the formation of Compound III, different decomposition pathways can occur. As the hydroperoxyl radicals are close to the heme group, one possibility is the oxidation of the porphyrin ring. This oxidation results in the cleavage of the carbon-carbon bonds that connect the pyrrole rings, leading to the destruction of the porphyrin ring and the formation of an open-chain tetra-pyrrole structure (biliverdin). This pathway can be confirmed by the detection of free Fe(III) in solution (heme bleaching). The destruction of the porphyrin ring has been observed in many hemoproteins (hemoglobin, myoglobin, HRP, MP11, MP8 etc.)[34-36] The addition of substrate in excess can in some cases limit the deactivation of peroxidases, as the substrate would compete with $\mathrm{H}_{2} \mathrm{O}_{2}$ for binding with the iron(III).[31,37]

\section{Insert Figure 7}

Secondly, the catalytic functions of MP8 and MP11 depend strongly on the coordination of His18 to the iron(III) (push effect) and this coordination depends on the $\mathrm{pH}$ conditions. Therefore, under acidic conditions, under which His18 is protonated, their catalytic function is almost negligible, limiting their use to either neutral or alkaline conditions. Finally, the use of MP8 and MP11 is also hampered by their tendency to aggregate in aqueous alkaline solutions, even at low concentrations $(\sim 2 \mu \mathrm{M})$. Two main mechanisms are involved in this aggregation: (i) a concentration-dependent intermolecular coordination, where the N-terminal amino group of Cys14 (MP8) or Val11 (MP11) is coordinated to the sixth axial position of iron(III) of another microperoxidase molecule, thus preventing the coordination of substrates, [8] (ii) $\pi$-stacking between the more exposed distal faces of two or more microperoxidase molecules.[38] Finally, another important disadvantage of both MP8 and MP11 is their relatively low selectivity, due to the lack of a specific catalytic pocket.

\section{Immobilization strategies}

The stability and selectivity limitations of microperoxidases can be effectively addressed by their immobilization in solid matrices. Such actions can also lead to the added benefit of recycling MP8 and MP11 from the reaction media. The immobilization matrix must preserve maximal enzymatic activity, i.e. maximal loading and minimal leaching, while not hindering the diffusion of reactants/products to and from the enzyme's active site. The field of enzyme immobilization has been under investigation for decades,[39] which allowed the development of four main types of immobilization that are surface adsorption, covalent binding, pore inclusion and entrapment (Fig. 8).[2,40,41] The two first cases concern the immobilization of enzymes at the external surface of materials either via weak reversible interactions (van der Waals, electrostatic, hydrophobic/hydrophilic...) or via the formation of irreversible covalent bonds. The major limitation of these two methods is that the enzyme may not be protected from the external conditions and may easily be denatured. For the pore inclusion and the entrapment methods, the enzymes are confined into either the internal surface of a porous solid matrix or in the inter-particle porosity of the matrix, respectively. Enzymes are generally protected against denaturing conditions by using these approaches, since the host matrices can create a threedimensional stabilizing microenvironment through specific host-guest interactions and through confinement effects. The choice of the immobilization strategy strongly depends on the enzyme/host matrix couple and on the targeted biocatalytic process. Considering the limitations of microperoxidases (low stability and selectivity, easy aggregation...) 
and their size, the pore inclusion strategy has been favored, compared to the other three immobilization methods as it allows -provided there is a size matching between the pores and the enzyme- to isolate single enzymes inside each cavity, limiting their aggregation.

\section{Insert Figure 8}

\section{MP8 AND MP11 IMMOBILIZATION IN METAL-ORGANIC FRAMEWORKS}

The solid supports that have been mostly studied for the pore inclusion of enzymes are mesoporous (alumino)silica[42] and clays minerals.[43] Such materials have been applied to many enzymes, but very rarely to MPs.[44-46] MPs have mainly been adsorbed or covalently bound onto surfaces that provided biodevices with interesting properties, but they did not provide protective environments to MPs.[11,47-49] This may be due to the nature of the materials. While they have robust structures and/or well-established biocompatibility, they may suffer from enzyme leaching as their interactions with biological molecules may not be sufficient to stabilize enzymes within their structure. Subsequently, their functionalization or association with organic moieties (e.g. biopolymers, crosslinking agents...) is often required to increase the interactions between the enzymes and the host material.[50] Thus, the association of different materials may be necessary to provide a hybrid material that combines inorganic-organic characteristics. Quite recently, Metal-Organic Frameworks (MOFs) have been proposed as a new alternative for enzyme immobilization that could possibly address certain limitations of the traditional matrices.[51-54] MOFs are a class of crystalline, porous, hybrid materials composed by the assembly of inorganic and organic building blocks, giving rise to infinite 3D porous networks. Their unique characteristics: hybrid nature, high and ordered porosity (up to $90 \%$ free volume), high internal surface areas (> $6000 \mathrm{~m}^{2} / \mathrm{g}$ ), and almost unlimited chemical and structural tunability have rendered MOFs attractive candidates for a vast number of applications (gas storage/separation, catalysis, drug delivery etc.).[55-57] The reports using MOFs for the immobilization of MP8 and MP11 seem promising to expand the use of these mini-enzymes for practical applications.

The first study on microperoxidase immobilization on MOFs was reported back in 2006 by Pisklak et al.[58] The MP11@MOF hybrid material showed an enhanced catalytic activity over the free enzyme for the catalytic degradation of the dye methylene blue. A comparison with MP11 immobilized in the 1D cavities of a hybrid periodic mesoporous organosilica demonstrated that the 3D porosity of the MOF allowed enhanced kinetics and resulted in an increased degradation compared to that observed with the organosilica matrix.[58]

Lykourinou et al. used a mesoporous MOF based on Tb and the 4,4',4"-s-triazine-2,4,6-triyltribenzoate ligand (TATB), named Tb-mesoMOF, for the immobilization of MP11.[59] The two large cavities of Tb-mesoMOF (3.9 and $4.7 \mathrm{~nm}$ in diameter) allowed the inclusion of MP11 (Fig. 9). The activity of MP11@TbmesoMOF was evaluated through the catalytic oxidation of 3,5-di-t-butylcatechol to o-quinone and compared with that of the free enzyme and that of MP11 immobilized in a typical mesoporous silica material (MCM-41, MCM= Mobil Composition of Matter ). While free MP11 showed higher reaction rates since the immobilized enzymes had to surpass diffusion limitations, it quickly lost its activity due to aggregation. The MP11@MCM-41 biocatalyst showed severe leaching due to the lack of specific interaction with the enzyme and showed a $60 \%$ decrease in activity after the first catalytic cycle. On the contrary, MP11@Tb-mesoMOF showed no leaching over seven cycle, highlighting the importance of the framework's hybrid nature for the stabilization of the immobilized MP11.[59] The interactions of MP11 with Tb-mesoMOF were further investigated via Raman spectroscopy.[60] It revealed that MP11 strongly interacted with the MOF framework, through $\pi-\pi$ interactions of its porphyrin ring with the conjugated systems of the TATB ligand (triazine and benzene 
rings). MP11 did not show any strong specific interactions with MCM-41, in agreement with the important leaching from the matrix.[60]

\section{Insert Figure 9}

The TATB ligand combined with $\mathrm{Al}^{3+}$ cations can form a 3D mesoporous MOF, PCN-333 (PCN = Porous Coordination Network) with larger cavities than those of Tb-mesoMOF (4.2 and $5.5 \mathrm{~nm}$ in diameter).[61] PCN-333(Al) was used for the pore inclusion of MP11 and resulted in very high loadings of $0.89 \mathrm{~g} / \mathrm{g}$ MOF. However, the immobilized enzyme showed a decreased activity, possibly due to its aggregation inside the large cavities of PCN333(Al), which allowed the immobilization of more than one enzyme per cavity. These results demonstrate the importance of carefully selecting the porous matrix based on the characteristics of the selected enzyme. Nonetheless, MP11@PCN-33(Al) showed good recyclability over 5 cycles, whereas MP11 immobilized in the mesoporous silica SBA-15 (Santa Barbara Amorphous) lost $80 \%$ of its activity after the second cycle.[61]

\section{Insert Figure 10}

C. Gong et al. exploited the use of MP11@Tb-mesoMOF and MP11@PCN-333(Al) for the development of a novel electrochemical $\mathrm{H}_{2} \mathrm{O}_{2}$ biosensors (Fig. 11).[62,63] For the preparation of the electrode, a macroporous 3D carbon (pore diameter: $25 \mu \mathrm{m}$ ) was used as support for the synthesis of the mesoporous MOFs. The MOF particles were densely formed on the channel walls, increasing their thickness from $1 \mu \mathrm{m}$ to $3 \mu \mathrm{m}$. MP-11 was immobilized inside the MOF cavities by simply immersing the MOF/3D-carbon electrode in a solution containing the enzyme. The bioelectrodes exhibited a wide linear range for $\mathrm{H}_{2} \mathrm{O}_{2}$ concentrations and a low limit of detection. Moreover, they showed good stability and selectivity, superior to that of MP11@3D-carbon, highlighting the importance of the confinement of MP11 in the MOFs. $[62,63]$

\section{Insert Figure 11}

Finally, in a different study, MP8 was immobilized in the mesopores (2.9 and $3.4 \mathrm{~nm}$ in diameter) of the ultra-stable MOF, MIL-101(Cr) (MIL= Matériaux Institut Lavoisier).[64] MP8 retained a full catalytic activity after the immobilization and showed an enhanced resistance to acidic and oxidative conditions, compared to those of the free enzyme, demonstrating the protective role of the MOF framework. MP8@MIL-101(Cr) was able to be reused at least 5 times and showed a long-term stability. Most importantly, it was demonstrated that the MOF matrix could act in synergy with MP8 and selectively enhance the oxidation rate of organic dyes (methyl orange) compared to free MP8 (Fig. 12).

\section{Insert Figure 12}

The positively charged framework of MIL-101(Cr) promoted the pre-concentration of methyl orange inside its cavities and in proximity to the immobilized MP8, via strong electrostatic interactions. This attraction resulted in higher reaction rates of degradation for the immobilized MP8 compared to the enzyme in solution, despite the diffusion barrier of immobilized systems. This work highlights the use of MOF as active components in catalytic processes instead of simple immobilization matrices.[64]

\section{CONCLUSION}


Several groups have immobilized MP8 or MP11 into MOFs to develop efficient biocatalysts. The catalytic activity of immobilized MPs was preserved even if they sometimes exhibited lower reaction rates than free enzyme due to a slower diffusion of reactant, a phenomemom commonly observed in immobilization matrices. The highly porous and hybrid nature of MOF appeared to be an important parameter that allowed the 3D enzyme confinement and provided interactions between the framework and MPs. These features enable enzyme stabilization and efficiently minimize its leaching. The biocatalysts can thus be recycled over several cycles and MPs are protected from denaturating conditions, allowing catalytic activity under non natural environments (acidic and oxidative media). The small size of MPs does not require ultra-large pores $(>4 \mathrm{~nm}$ ) for their pore inclusion, which renders their immobilization into water stable MOFs easily conceivable.

The catalytic activity of MP@MOF materials has been mainly tested for oxidation reactions. In some cases, the MOFs framework could favor the catalytic reaction (higher reaction rate) due to interactions between the MOF and the reactants, leading to their pre-concentration at the vicinity of the enzyme. The MOF matrix induced a charge-based selectivity to the oxidation reaction. However, so far, stereoselective oxidation via oxygen transfer, that would be of very high interested, has not yet been reported. The presence of functional substituants (e.g. chiral groups) within the MOFs frameworks, which might influence immobilized MPs reactivity and favor the stereoselectivity of reactions, has not been investigated yet.

\section{Acknowledgements}

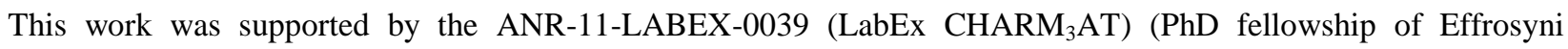
Gkaniatsou)

\section{REFERENCES}

1. DiCosimo R, McAuliffe J, Poulose AJ and Bohlmann G. Chem. Soc. Rev. 2013; 42: 6437-6474.

2. Sheldon RA and van Pelt S. Chem. Soc. Rev. 2013; 42: 6223-6235.

3. Kirk O, Borchert TV and Fuglsang CC. Curr. Opin. Biotechnol. 2002; 13: 345-351.

4. Secundo F. Chem. Soc. Rev. 2013; 42: 6250-6261.

5. Poulos TL. Chem. Rev. 2014; 114: 3919-3962.

6. Ascenzi P, Ciaccio C, De Simone G, Santucci R and Coletta M. J. Porphyr. Phthalocyanines 2017; 21 : 1-9.

7. Chen Z, Chen J, Ma N, Zhou H and Cong Z. J. Porphyr. Phthalocyanines 2018; 22: 831-836.

8. Marques HM. Dalton Trans. 2007; 39: 4371-4385.

9. Aron J, Baldwin DA, Marques HM, Pratt JM and Adams PA. J. Inorg. Biochem. 1986; 27: 227-243.

10. de Lauzon S, Mansuy D and Mahy J-P. Eur. J. Biochem. 2002; 269: 470-480.

11. Korri-Youssoufi H, Desbenoit N, Ricoux R, Mahy J-P and Lecomte S. Mater. Sci. Eng. C 2008; 28: 855-860.

12. Marques HM, Baldwin DA and Pratt JM. J. Inorg. Biochem. 1987; 29: 77-91.

13. Rodriguez-Lopez JN, Lowe DJ, Hernandez-Ruiz J, Hiner ANP, Garcia-Canovas F and Thorneley RNF. J. Am. Chem. Soc. 2001 ; 123: 11838-11847.

14. Wang R and de Visser SP. J. Inorg. Biochem. 2007; 101: 1464-1472. 
15. Primus J-L, Grunenwald S, Hagedoorn P-L, Albrecht-Gary A-M, Mandon D and Veeger C. J. Am. Chem. Soc. 2002; 124: 1214-1221.

16. Wang J-S, Baek HK and Van Wart HE. Biochem. Biophys. Res. Commun. 1991; 179: 1320-1324.

17. Low DW, Winkler JR and Gray HB. J. Am. Chem. Soc. 1996; 118: 117-120.

18. Díaz Torres E and Ayala M, eds. Biocatalysis Based on Heme Peroxidases: Peroxidases as Potential Industrial Biocatalysts. New York: Springer-Verlag; 2010.

19. Dallacosta C, Monzani E and Casella L. J. Biol. Inorg. Chem. 2003; 8: 770-776.

20. Adams PA. J. Chem. Soc. Perkin Trans. 1990; 2: 1407-1414.

21. Cunningham ID, Bachelor JL and Pratt JM. J. Chem. Soc. Perkin Trans. 1991; 2: 1839-1843.

22. Ricoux R, Boucher J-L, Mansuy D and Mahy J-P. Eur. J. Biochem. 2001; 268: 3783-3788.

23. Ricoux R, Lukowska E, Pezzotti F and Mahy J-P. Eur. J. Biochem. 2004; 271: 1277-1283.

24. Longoria A, Tinoco R and Vázquez-Duhalt R. Chemosphere 2008; 72: 485-490.

25. Hamid M and Khalil-ur-Rehman. Food Chem. 2009; 115: 1177-1186.

26. Shaffiqu TS, Roy JJ, Nair RA and Abraham TE. Appl. Biochem. Biotechnol. 2002; 102-103: 315-326.

27. Huang X and Groves JT. J. Biol. Inorg. Chem. 2017; 22: 185-207.

28. Osman AM, Koerts J, Boersma MG, Boeren S, Veeger C and Rietjens IMCM. Eur. J. Biochem. 1996; 240: 232238 .

29. Boersma MG, Primus J-L, Koerts J, Veeger C and Rietjens IMCM. Eur. J. Biochem. 2000; 267: 6673-6678.

30. Dorovska-Taran V, Posthumus MA, Boeren S, Boersma MG, Teunis CJ, Rietjens IMCM and Veeger C. Eur. J. Biochem. 1998; 253: 659-668.

31. Valderrama B, Ayala M and Vazquez-Duhalt R. Chem. Biol. 2002; 9: 555-565.

32. Adediran SA and Lambeir A-M. Eur. J. Biochem. 1989; 186: 571-576.

33. Wariishi H, Akileswaran L and Gold MH. Biochemistry 1988; 27: 5365-5370.

34. Nagababu E and Rifkind JM. Biochem. Biophys. Res. Commun. 2000; 273: 839-845.

35. Spector A, Zhou W, Ma W, Chignell CF and Reszka KJ. Exp. Eye Res. 2000; 71: 183-194.

36. Nakajima R and Yamazaki I. J. Biol. Chem. 255: 2067-2071.

37. Hiner ANP, Ruiz JH, López JNR, Cánovas FG, Brisset NC, Smith AT, Arnao MB and Acosta M. J. Biol. Chem. 2002; 277: 26879-26885.

38. Caputi L, Di Tullio A, Di Leandro L, De Angelis F and Malatesta F. Biochim. Biophys. Acta 2005; 1725: 71-80.

39. Reymond J-L, ed. Enzyme Assays: High-Throughput Screening, Genetic Selection and Fingerprinting. Weinheim: Wiley-VCH; 2006.

40. Sheldon RA. Adv. Synth. Catal. 2007; 349: 1289-1307.

41. Dwevedi A. In Enzyme Immobilization. Cham: Springer International Publishing, 2016; 21-44.

42. Hartmann M and Kostrov X. Chem. Soc. Rev. 2013; 42: 6277-6289. 
43. Mousty C and Prevot V. Anal. Bioanal. Chem. 2013; 405: 3513-3523.

44. Mohajerani B, Soleymani-Jamarani M, Nazari K, Mahmoudi A and Moosavi-Movahedi AA. J. Mol. Catal. Chem. 2008; 296: 28-35.

45. Araujo JC, Prieto T, Prado FM, Trindade FJ, Nunes GLC, dos Santos JG, Di Mascio P, Castro FL, Fernandes GJT, Fernandes VJ, Araujo AS, Politi MJ, Brochsztain S, Nascimento OR and Nantes IL. J. Nanosci. Nanotechnol. 2007; 7: 3643-3652.

46. Wang Q, Yang Q and Su B. Electrochim. Acta 2015; 161: 290-296.

47. Yarman A, Nagel T, Gajovic-Eichelmann N, Fischer A, Wollenberger U and Scheller FW. Electroanalysis 2011; 2011: 611-618.

48. Huang W, Jia J, Zhang Z, Han X, Tang J, Wang J, Dong S and Wang E. Biosens. Bioelectron. 2003; 18: 12251230.

49. Astuti Y, Topoglidis E and Durrant JR. Anal. Chim. Acta 2011; 686: 126-132.

50. Zdarta J, Meyer A, Jesionowski T and Pinelo M. Catalysts 2018; 8: 92-118.

51. a) Gkaniatsou E, Sicard C, Ricoux R, Mahy J-P, Steunou N and Serre C. Mater. Horiz. 2017; 4: 55-63, b) Doonan C, Riccò R, Liang K, Bradshaw D and Falcaro P. Acc. Chem. Res. 2017; 50: 1423-1432, c) Majewski MB, Howarth AJ, Li P, Wasielewski MR, Hupp JT and Farha OK. CrystEngComm 2017; 19: 4082-4091; d) Chen Y and Ma S. Dalton Trans. 2016; 45: 9744-9753.

52. a) Feng D, Liu T-F, Su J, Bosch M, Wei Z, Wan W, Yuan D, Chen Y-P, Wang X, Wang K, Lian X, Gu Z-Y, Park J, Zou X and Zhou H-C, Nat. Commun. 2015;6:5979, b) Li P, Chen Q, Wang T C, Vermeulen NA, Mehdi BL, Dohnalkova A, Browning ND, Shen D, Anderson R, Gómez-Gualdrón DA, Cetin FM, Jagiello J, Asiri AM, Stoddart JF and Farha OK. Chem 2018; 4: 1022-1034.

53. Liang K, Ricco R, Doherty CM, Styles MJ, Bel S, Kirby N, Mudie S, Haylock D, Hill AJ, Doonan CJ and Falcaro P. Nat. Commun. 2015; 6: 1-8

54. C Huo J, Aguilera-Sigalat J, El-Hankari S and Bradshaw D. Chem. Sci. 2015; 6: 1938-1943.

55. Zhou H-C, Long JR and Yaghi OM. Chem. Rev. 2012; 112: 673-674.

56. Zhou H-C and Kitagawa S. Chem. Soc. Rev. 2014; 43: 5415-5418.

57. Maurin G, Serre C, Cooper A and Férey G. Chem. Soc. Rev. 2017; 46: 3104-3107.

58. Pisklak TJ, Macías M, Coutinho DH, Huang RS and Balkus KJ. Top. Catal. 2006; 38: 269-278.

59. Lykourinou V, Chen Y, Wang X-S, Meng L, Hoang T, Ming L-J, Musselman RL and Ma S. J. Am. Chem. Soc. 2011; 133: 10382-10385.

60. Chen Y, Han S, Li X, Zhang Z and Ma S. Inorg. Chem. 2014; 53: 10006-10008.

61. Feng D, Liu T-F, Su J, Bosch M, Wei Z, Wan W, Yuan D, Chen Y-P, Wang X, Wang K, Lian X, Gu Z-Y, Park J, Zou X and Zhou H-C. Nat. Commun. 2015; 6: 5979.

62. Gong C, Shen Y, Chen J, Song Y, Chen S, Song Y and Wang L. Sens. Actuators B Chem. 2017; 239: 890-897.

63. Gong C, Chen J, Shen Y, Song Y, Song Y and Wang L. RSC Adv. 2016; 6: 79798-79804. 
64. Gkaniatsou E, Sicard C, Ricoux R, Benahmed L, Bourdreux F, Zhang Q, Serre C, Mahy J-P and Steunou N. Angew. Chem. Int. Ed. 2018; 57: 1-7. 


\section{FIGURE CAPTIONS}

Fig. 1. Molecular structure of iron(III)-protoporphyrin IX (heme). Fe(III) atom in orange, $\mathrm{N}$ atoms in blue, $\mathrm{O}$ atoms in red, $\mathrm{C}$ atoms in green. $\mathrm{H}$ atoms have been omitted for clarity.

Fig. 2. Molecular structure of MP8 and MP11. The amino acid residues numbering derives from the parent Cytochrome c from horse heart.

Fig. 3. Dependence of His 18 coordination as a function of $\mathrm{pH}$ in MP8 and MP11[12]

Fig. 4. Heterolytic cleavage of $\mathrm{H}_{2} \mathrm{O}_{2}$, assisted by the distal and proximal aminoacids of Cytochrome c peroxidase and formation of Compound $\mathrm{I}(\mathrm{Fe}$ atoms in orange, $\mathrm{N}$ atoms in blue, $\mathrm{O}$ atoms in red, $\mathrm{H}$ atoms in white and carbon atoms in grey expect carbon atoms of protoporphyrin IX, which are shown in green).

Fig. 5. Catalytic cycle of MP8 and MP11 (Fe atoms in orange, $\mathrm{N}$ atoms in blue, $\mathrm{O}$ atoms in red and carbon atoms in grey expect carbon atoms of protoporphyrin IX, which are shown in green).

Fig. 6. Oxygen rebound mechanism of aliphatic hydroxylation catalyzed by MP8 and MP11. (Fe atoms in orange, N atoms in blue, O atoms in red and carbon atoms in grey expect carbon atoms of protoporphyrin IX, which are shown in green).

Fig. 7. Schematic illustration of the deactivation pathway of peroxidases in excess of $\mathrm{H}_{2} \mathrm{O}_{2}$. The $\mathrm{CO}$ groups in the deactivated molecule are shown perpendicular to the heme for clarity sake of the schematic illustration. They should be on the same plane than the heme.

Fig. 8. Different strategies employed in the immobilization of enzymes.

Fig. 9. (a) Molecular structure of MP-11; (b) $3.9 \mathrm{~nm}$-diameter cage, and (c) $4.7 \mathrm{~nm}$-diameter cage in Tb-mesoMOF. Reprinted with permission from Ref. 57. Copyright 2011 American Chemical Society.

Fig. 10. TATB ligand used for the synthesis of PCN-333(Al) and the resulting three different cages of the MOF. Adapted and Reprinted from Ref. [61] with permission from Springer Nature, Copyright 2015.

Fig. 11. Schematic illustration of the fabrication process of the $\mathrm{H}_{2} \mathrm{O}_{2}$ electrochemical biosensor of MP11@PCN-333(Al). Reprinted from Ref. [62] with permission from Elsevier, Copyright 2017.

Fig. 12. Selective bio-catalysis of MP8@MIL-101(Cr). The charge matching between methyl orange and MIL-101(Cr) promoted the pre-concentration of the dye in the cavities of the MOF and allowed its faster catalytic degradation by the immobilized MP8. Reprinted from Ref. [64] with permission from John Wiley and Sons, Copyright 2018. 


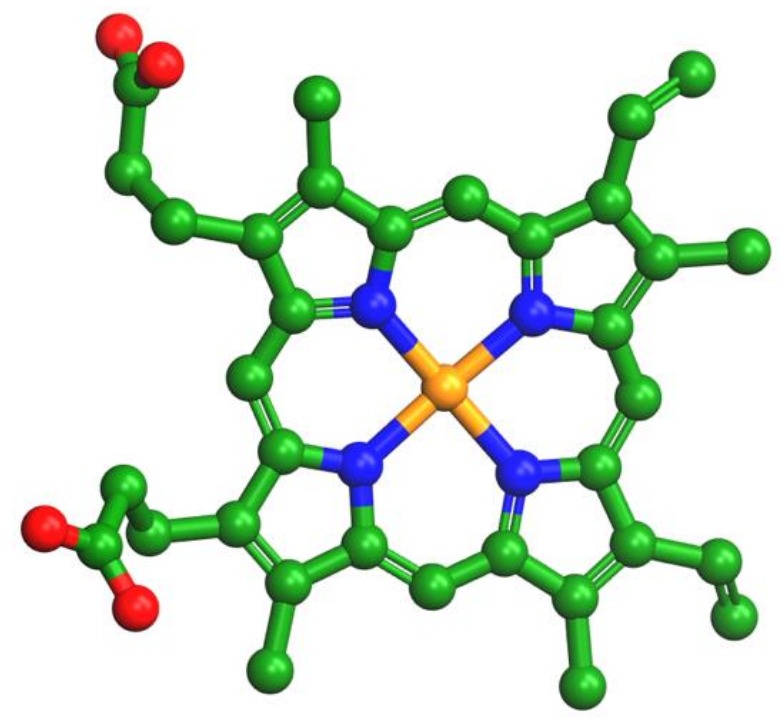

Figure 9. 


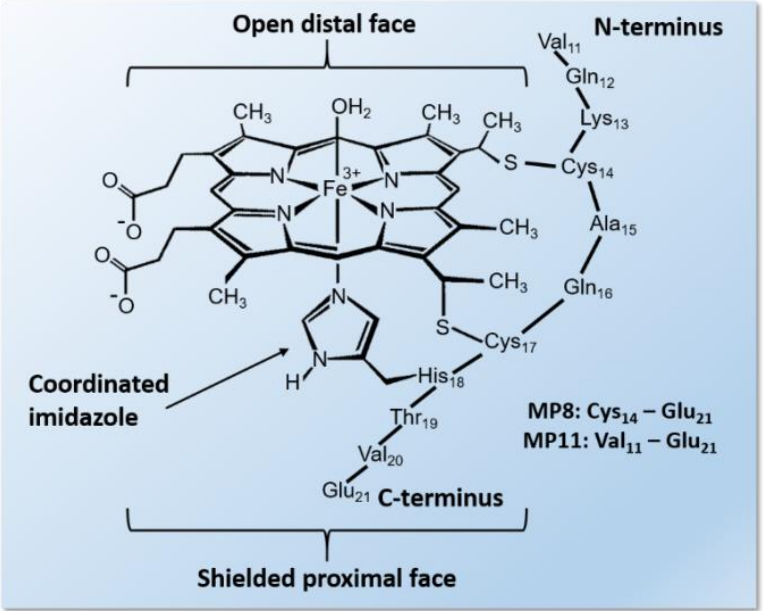

Figure 10. 


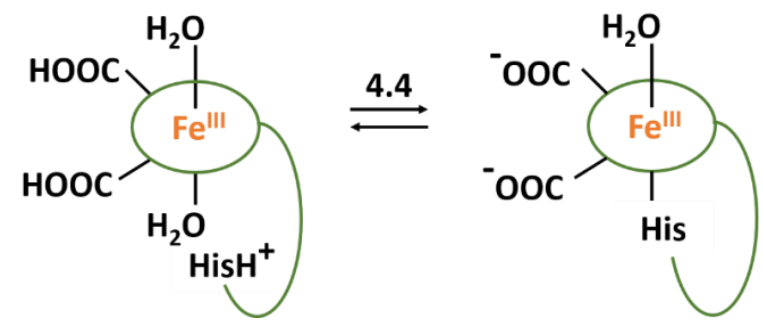

Figure 11. 


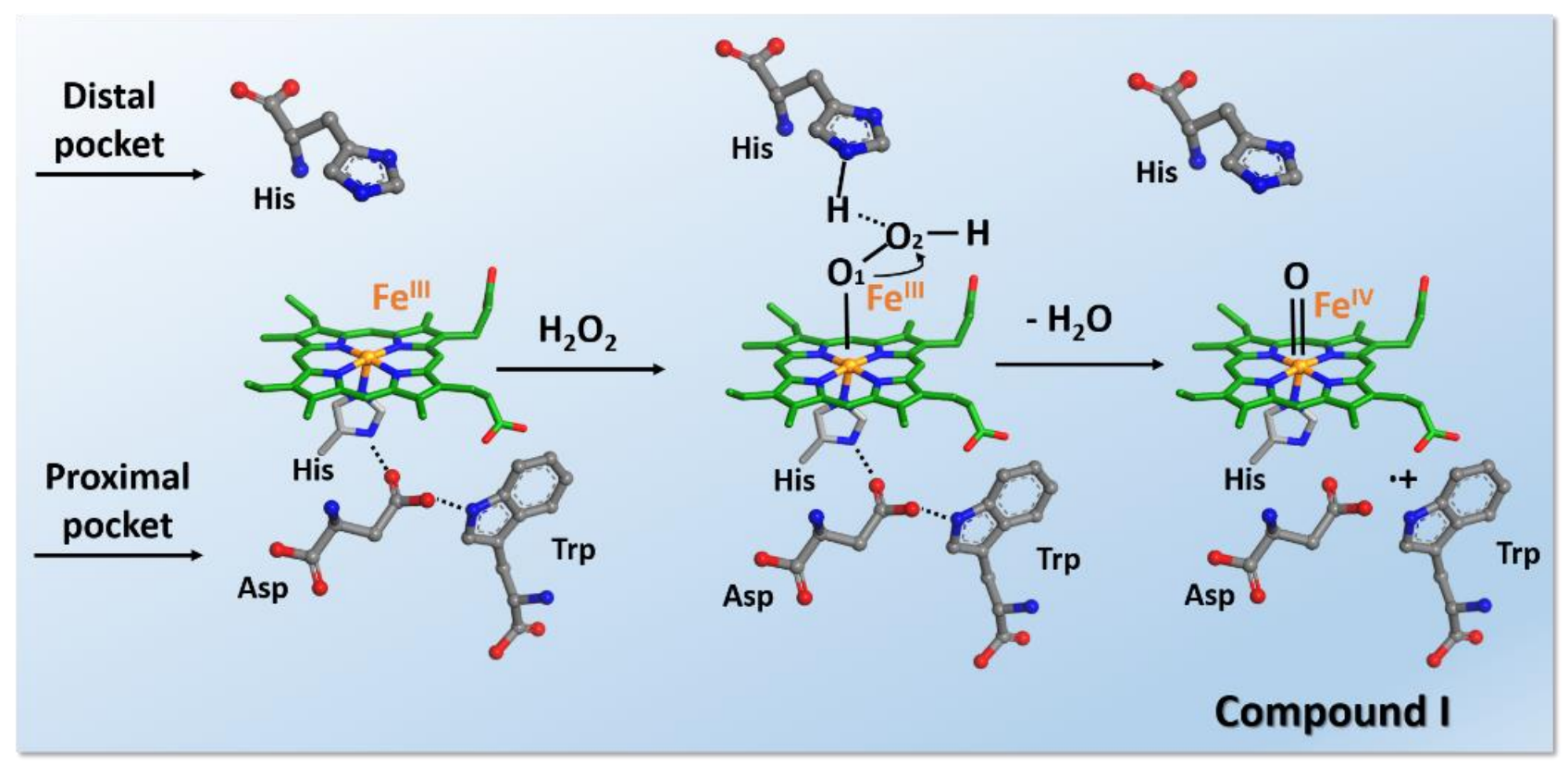

Figure 12. 


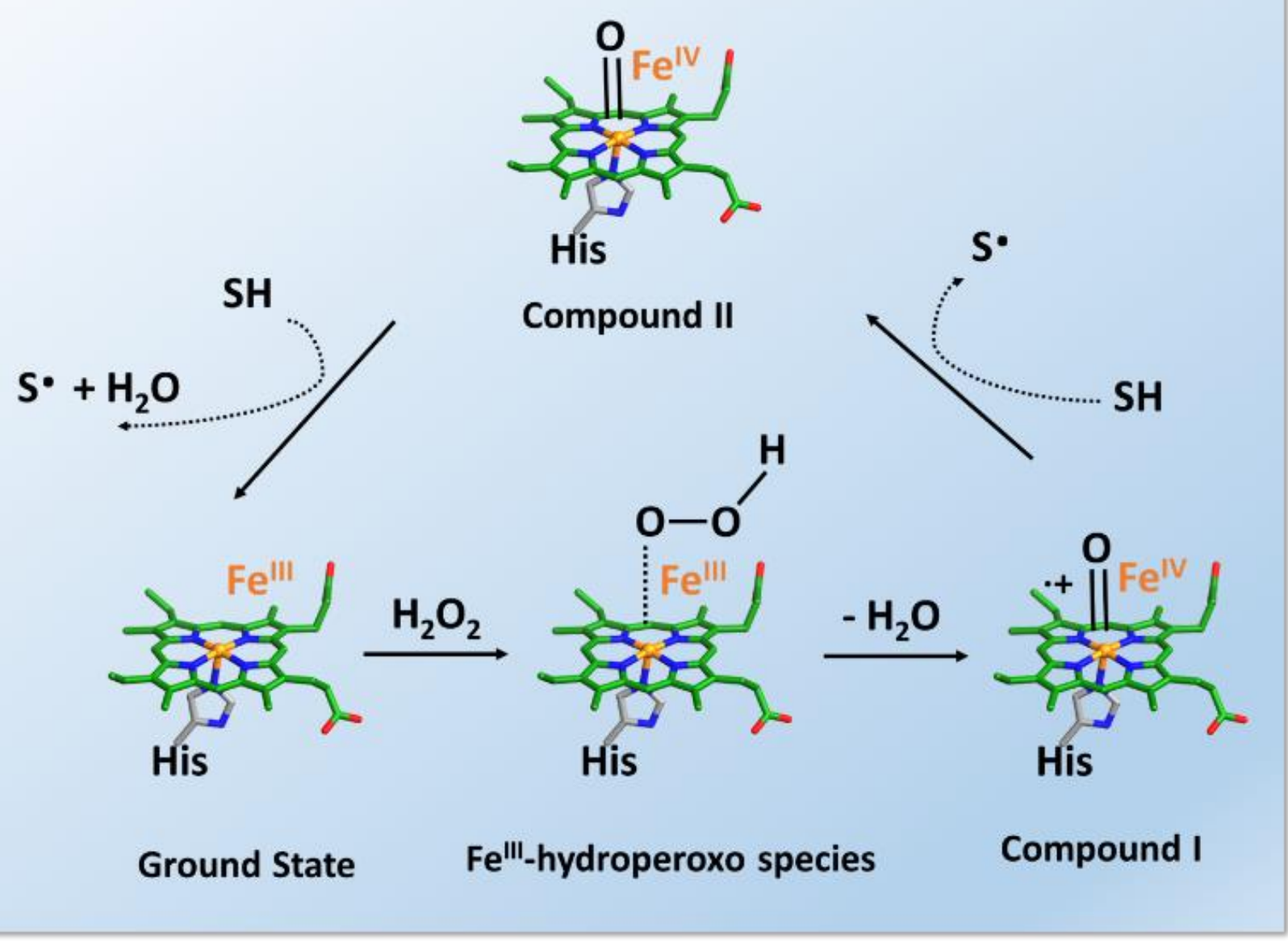

Figure 13. 


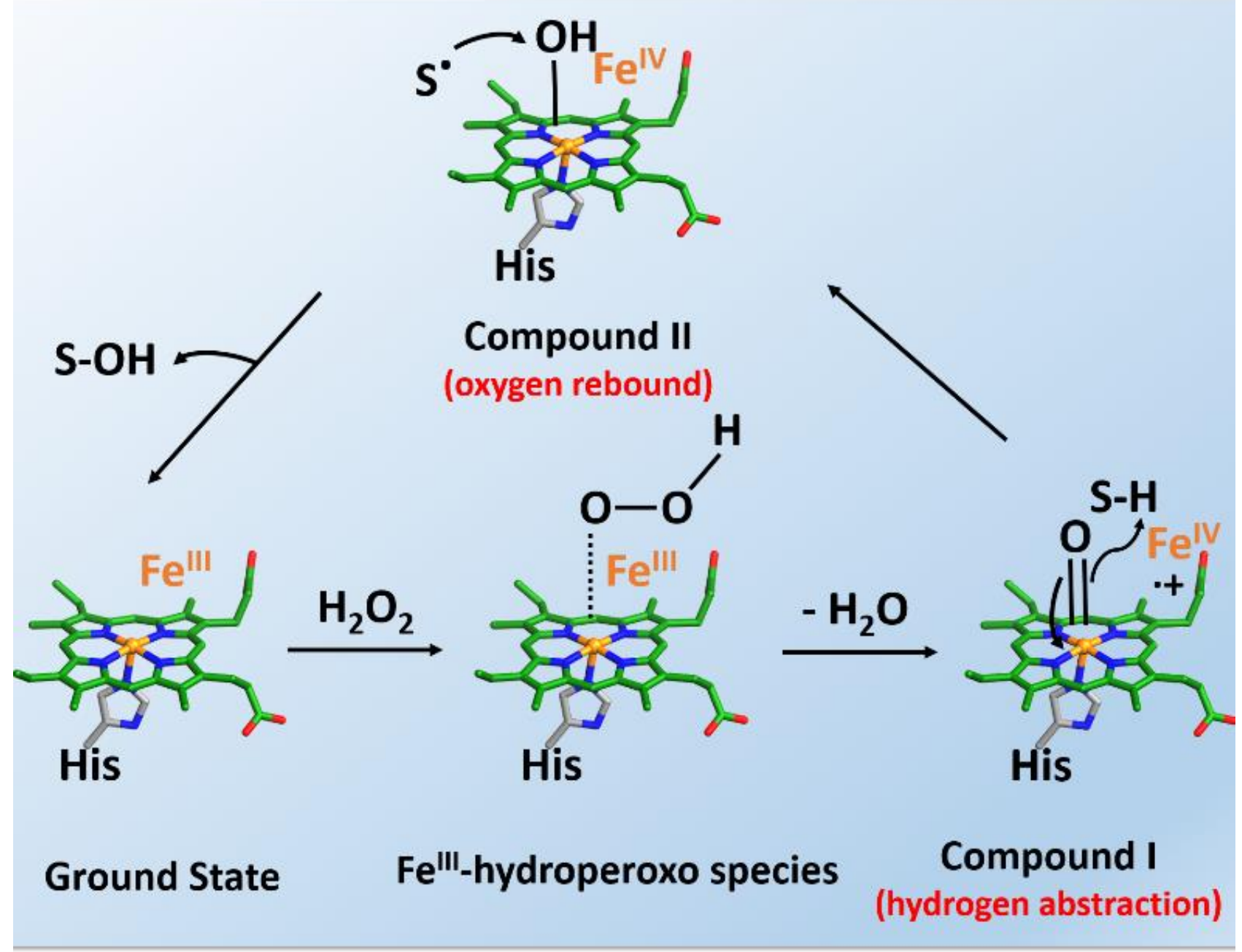

Figure 14. 


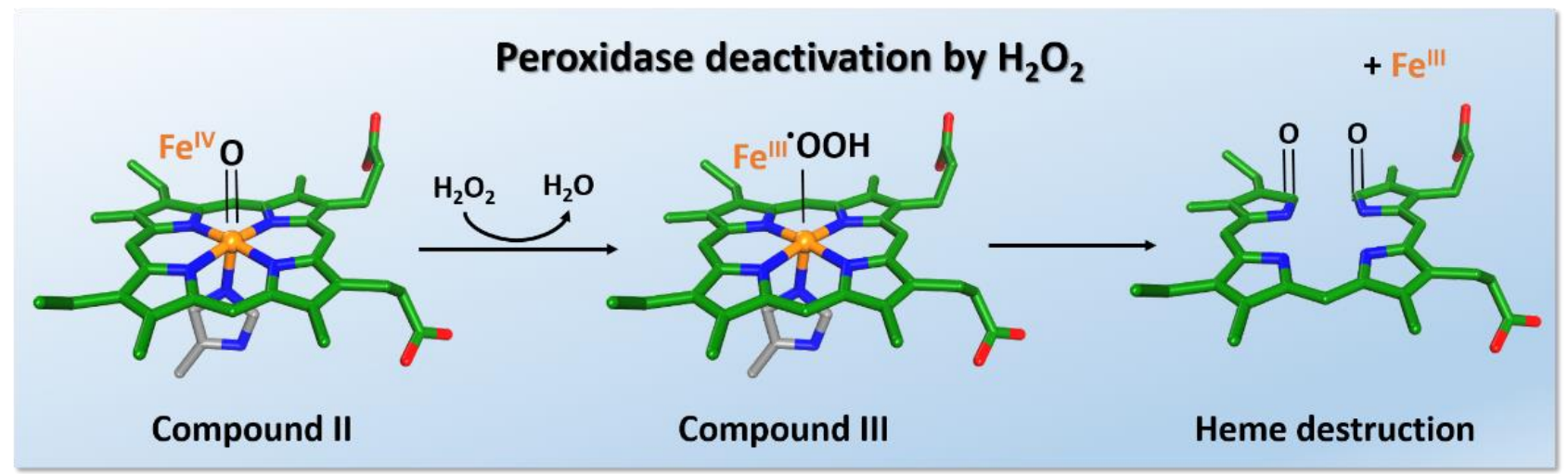

Figure 15. 


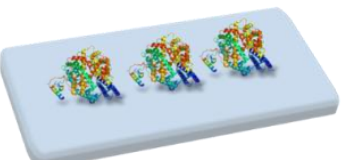

Surface adsorption

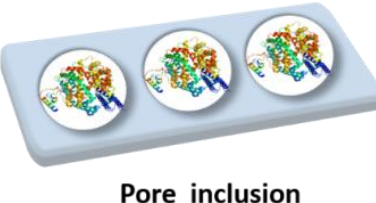

Pore inclusion

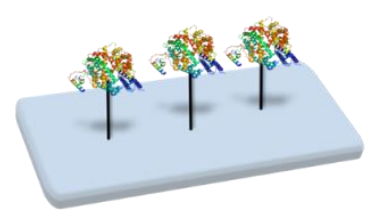

Covalent binding

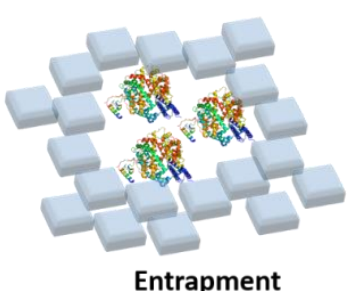

Figure 16. 


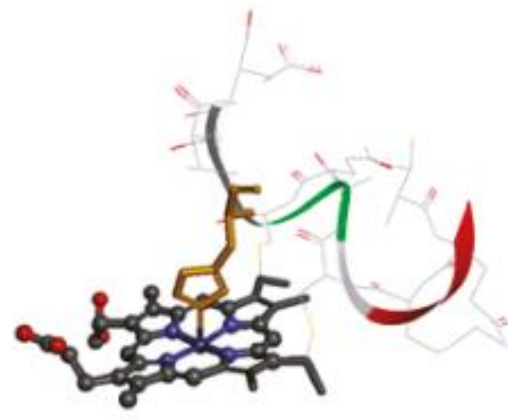

(a)

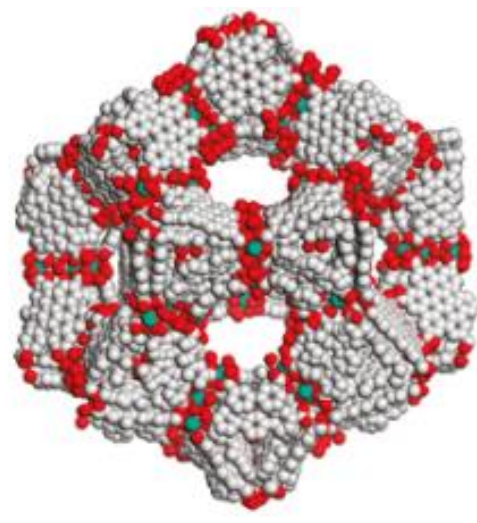

(b)

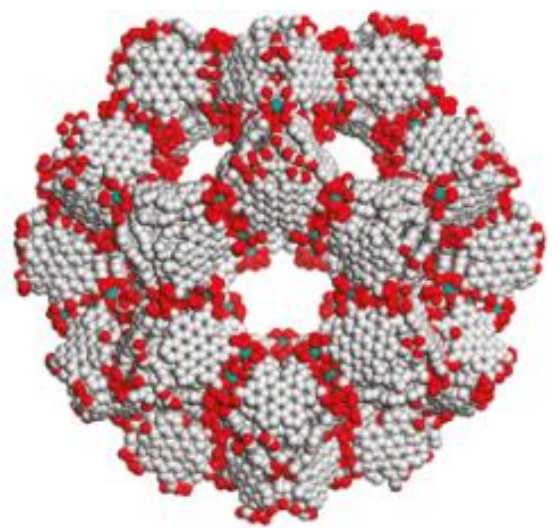

(c)

Figure 9. 


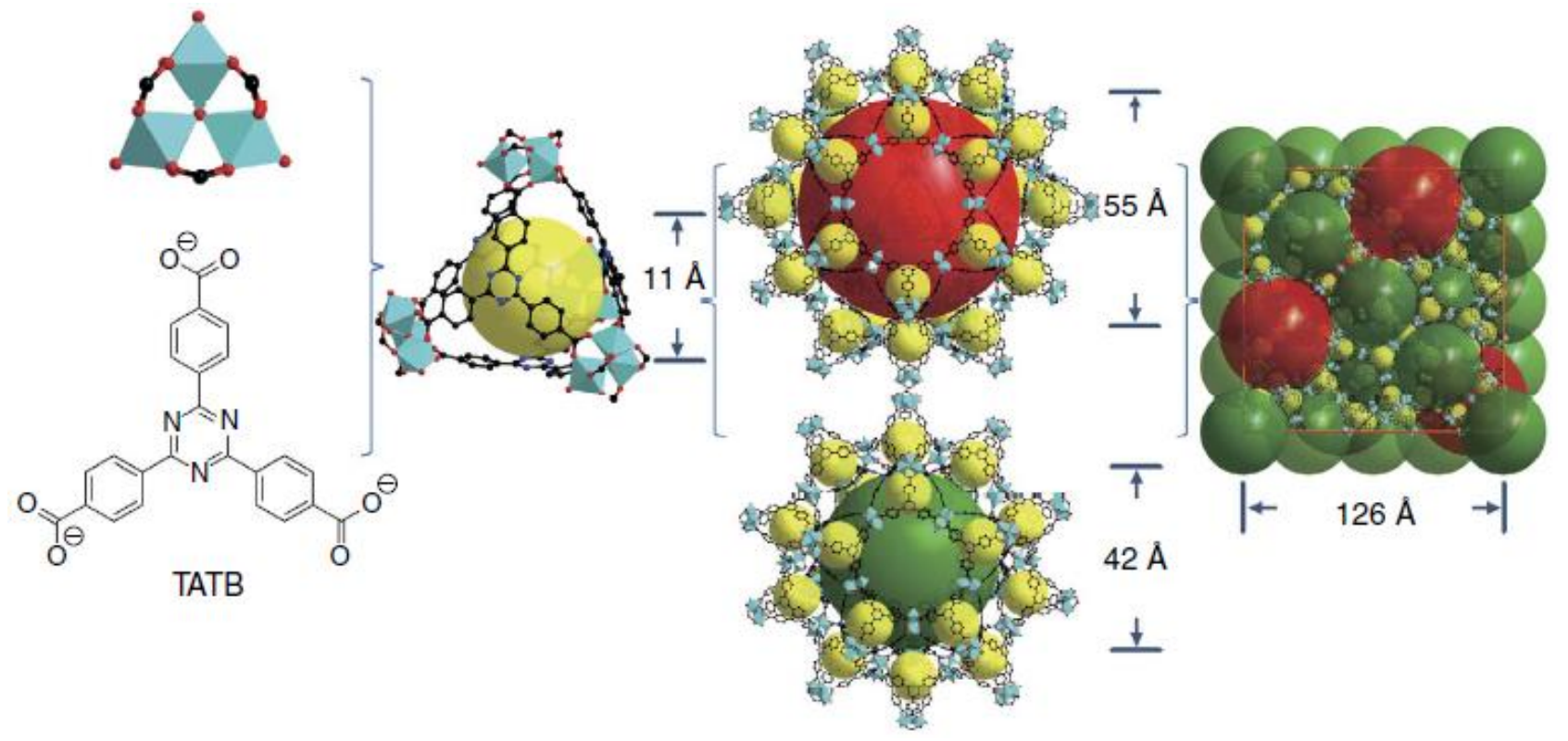

Figure 10. 


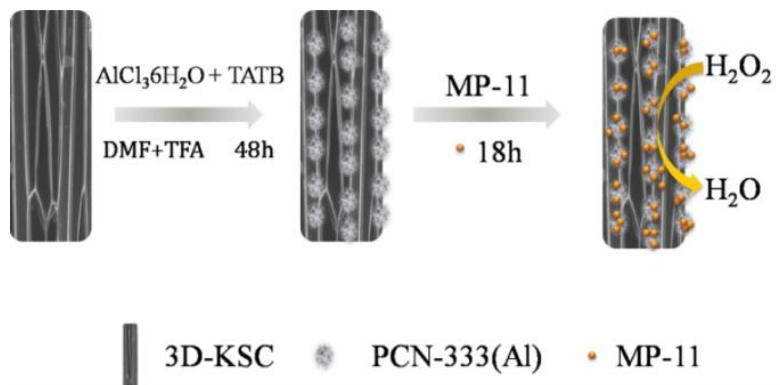

Figure 11. 


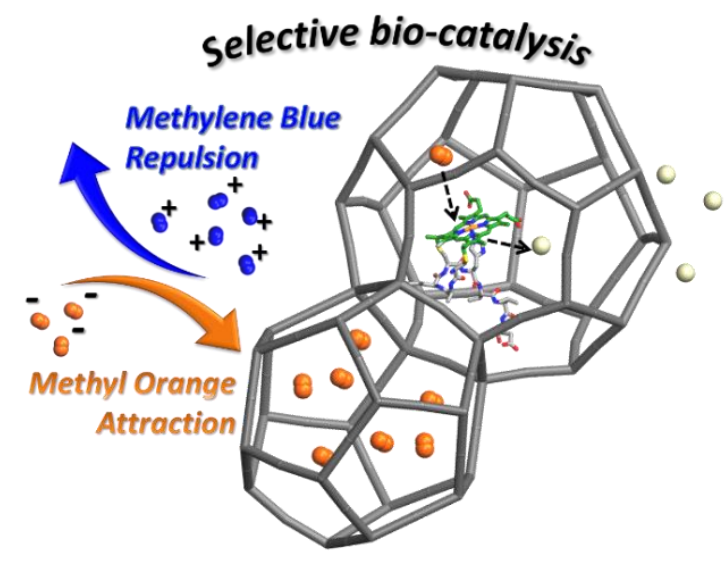

Figure 12. 